EUROPEAN HONORS COUNCIL

Note

\title{
Honors education in Spain - preliminary research findings
}

Anouska Jaspersen ${ }^{1}$, Jan-Douwe Krist ${ }^{1}$, Joost Pennings ${ }^{1}$, Maarten Hogenstijn ${ }^{2 *}$

1. Faculty of Geosciences, Utrecht University, The Netherlands

2. Research Centre for Talent Development in Higher Education and Society, Hanze University of Applied Sciences Groningen, The Netherlands

*Correspondence: ma.hogenstijn@pl.hanze.nl

Received: 1 February 2017; Accepted: 4 May 2017; Published: 8 May 2017

Keywords: honors, honours, higher education, talent development, excellence, Spain

\section{Introduction}

In 2015, Dr. Marca V.C. Wolfensberger published the book Talent Development in European Higher Education (Wolfensberger, 2015). The book entails the results of research on talent development in higher education in the Benelux, Nordic and German-speaking countries. It is part of the Honors in Europe research project, which aims to create and share knowledge about talent development initiatives in European higher education. Following publication of the book, the research project was expanded to Southern Europe and exploratory research on different countries was started. This note is focused on Spain. The exploratory research on honors education in Spain conducted so far is focused on finding and contacting Spanish higher education institutions to find out which initiatives in talent development already exist.

\section{Methods}

Three steps have been taken to achieve the current results.

First of all, a list of higher education institutions in Spain to be included in the research had to be determined. In addition, general information about these universities, like the number of students, had to be found. The main source for this information was the Spanish Ministry of Education (Ministerio de educación, cultura Y deporte 2015, p. 3).

As a next step, we used online information to determine which universities offer an honors program that corresponds to the definition used by Wolfensberger: 'Honors programs are selective study programs linked to higher education institutions. They are designed for motivated and gifted students who want to do more than the regular program offers. These programs have clear admission criteria and clear goals and offer educational opportunities that are more challenging and demanding than regular programs' (Wolfensberger, 2015, p.24). The websites of all institutions were scoured for information on the existence of such programs. 
At the same time, the websites were also searched for a valuable contact to whom we could send an e-mail. Usually this contact was a 'vicerector(a)' whose work field includes student affairs and/or academic organization, as this person would be best aware of the existence of such programs at the level of the whole institution.

The third step was to draw up an e-mail. In this e-mail general information was presented as well as two questions. These questions were as follows (shortened):

1. Does your organization offer special programs that correspond with the definition of an honors program?

2. Are there any other programs offered for talented students, or are they planned to be offered in the near future?

These e-mails were translated into Spanish and sent from a special account. Reminder emails were also sent from this account. When the response rate was found to be low, the same e-mail was sent again from the students' mail account of the first three authors.

\section{Preliminary results}

In total there are 83 universities in Spain. After consulting the websites of all universities, we were able to find five universities that offer an honors program that (at first sight) matches our definition.

Mail contact with the remaining 78 universities led to an answer of 24 universities. 21 Universities responded they don't offer an honors program, but four of these universities said they plan to start an honors program in the near future. Only two universities that responded said that they already offer a program that corresponds with our definition.

For now, we can only identify seven universities out of 83 that have a special program for excellent students. At this point in the research, it is difficult to draw general conclusions about the programs found and the institutions offering them. Programs range from a disciplinary program for law students, which consists of curricular and extracurricular activities and is orientated internationally; to an institution-wide program focusing on developing more general capacities in talented students, focusing on the fields 'innovation, impact and influence'. Institutions offering programs range from small-scale regional universities to larger universities with multiple campuses.

These preliminary findings suggest that the provision of honors programs is not of great importance in Spanish higher education in general. However, it is important to note that we have not received a reply from the majority of higher education institutions. Our research has not yet been completed. Gathering information on the plans for new honors programs and the characteristics of the existing ones will take place in the next phase of this research project.

\section{Conclusion and future perspectives}

As discussed under preliminary results, only 24 out of 78 universities have responded at the time of writing (January 2017). Since multiple e-mails have been sent, a next step to gather more results would be sending letters, or if possible, calling the universities. When more answers have been received, a more complete image of the provision of honors programs and the culture towards the concepts excellence and talent development in Spanish higher education can be painted. This would also open the possibility to look deeper into the 
factors causing this culture. Eventually, a complete list of all the honors programs in Spain should be formed, as well as an in-depth piece on the culture towards excellence in Spanish higher education.

\section{References}

Ministerio de educación, cultura Y deporte. (2015). Datos y Cifras del Sistema Universitario Español. Curso 2014/2015. Retrieved from: http://www.mecd.gob.es/dms/mecd/educacion$\underline{\mathrm{mecd} / a r e a s-e d u c a c i o n / u n i v e r s i d a d e s / e s t a d i s t i c a s-i n f o r m e s / d a t o s-c i f r a s / D a t o s-y-C i f r a s-d e l-~}$ $\underline{\text { SUE-Curso-2014-2015.pdf }}$

Wolfensberger, M. (2015). Talent Development in European Higher Education. Honors programs in the Benelux, Nordic and German-speaking countries. Heidelberg, New York, Dordrecht \& London: Springer International Publishing. Retrieved from:

http://doi.org/10.1007/978-3-319-12919-8 